OPEN ACCESS

Edited by:

Angel Lanas,

University of Zaragoza, Spain

Reviewed by:

Elif Sarıtaș Yüksel,

Izmir Kâtip Çelebi University, Turkey

Peter Philip Grimminger,

Johannes Gutenberg University

Mainz, Germany

Ivan Kristo,

Medical University of Vienna, Austria

${ }^{*}$ Correspondence:

Luigi Bonavina

luigi.bonavina@unimi.it

Specialty section

This article was submitted to

Gastroenterology,

a section of the journal

Frontiers in Medicine

Received: 23 December 2020

Accepted: 13 October 2021

Published: 02 November 2021

Citation:

Ferrari D, Siboni S, Riva CG,

Guerrazzi G, Lovece A and Bonavina L

(2021) Magnetic Sphincter Augmentation Outcomes in Severe Gastroesophageal Reflux Disease. Front. Med. 8:645592. doi: 10.3389/fmed.2021.645592

\section{Magnetic Sphincter Augmentation Outcomes in Severe Gastroesophageal Reflux Disease}

\author{
Davide Ferrari, Stefano Siboni, Carlo Galdino Riva, Guglielmo Guerrazzi, Andrea Lovece \\ and Luigi Bonavina*
}

Division of General and Foregut Surgery, Department of Biomedical Sciences for Health, Istituto di Ricovero e Cura a Carattere Scientifico (IRCCS) Policlinico San Donato, University of Milan, Milan, Italy

Introduction: Outcomes of laparoscopic procedures for gastroesophageal reflux disease (GERD) are variable depending on surgical expertise and/or patient-related factors. Some procedures may be inadequate in patients with severe disease. Effectiveness of laparoscopic magnetic sphincter augmentation (MSA) has not been extensively tested in patients with severe disease.

Methods: A prospectively collected database was analyzed to identify patients who underwent MSA at a single institution. Individuals who had previous esophago-gastric surgery were excluded. Severe GERD was defined as lower esophageal sphincter pressure $<5 \mathrm{mmHg}$, distal esophageal amplitude $<30 \mathrm{mmHg}$, Barrett's metaplasia, stricture or grade C-D esophagitis, and/or DeMeester score $>50$. Clinical characteristics and outcomes of patients with severe GERD were compared with those of patients with mild to moderate GERD who served as control group.

Results: Over the study period, a total of 336 patients met the inclusion criteria, and 102 (30.4\%) had severe GERD. The median follow-up was 24 months (IQR $=75)$ in severe GERD patients and 32 months $(I Q R=84)$ in those with non-severe GERD. Patients with severe GERD had a higher rate of dysphagia and higher GERD-HRQL scores. After the MSA procedure, symptoms, health-related quality of life scores, and proton-pump inhibitors consumption significantly decreased in both groups $(p<0.05)$. No difference between groups was found in the prevalence of severe post-operative dysphagia, the need for endoscopic dilation or device removal, and the DeMeester score.

Conclusion: Laparoscopic MSA is safe and effective in reducing symptoms, PPI use, and esophageal acid exposure also in patients with severe GERD.

Keywords: gastroesophageal reflux disease, hiatus hernia, esophagitis, Barrett's esophagus, DeMeester score, magnetic sphincter augmentation

\section{INTRODUCTION}

The pooled prevalence of gastro-esophageal reflux disease (GERD) is $14 \%$, with more than 1 billion of individuals affected and an enormous economic burden on health-care systems around the world (1). The novel laparoscopic magnetic sphincter augmentation (MSA) procedure was developed to offer a minimally invasive and standardized alternative to the total $\left(360^{\circ}\right)$ Nissen and 
the partial $\left(270^{\circ}\right)$ Toupet fundoplication. Both total and partial fundoplication still represent the surgical standard for GERD patients who are refractory to proton-pump inhibitors (PPI)

TABLE 1 | Distribution of pre-operative abnormalities in patients with severe GERD.

\begin{tabular}{lc}
\hline & $\mathbf{N}=\mathbf{1 0 2}$ (\%) \\
\hline LES pressure $<5 \mathrm{mmHg}$ & $33(32.4)$ \\
Distal esophageal amplitude $<30 \mathrm{mmHg}$ & $4(3.9)$ \\
Biopsy-proven Barrett's metaplasia & $34(33.3)$ \\
Presence of a stricture & $0(0)$ \\
Grade C or D esophagitis on endoscopy & $6(5.8)$ \\
DeMeester score $>50$ & $50(49)$
\end{tabular}

therapy, but these procedures are widely underused due to lack of reproducibility and broad variability in outcomes (2-4). Magnetic sphincter augmentation has proven safe and effective in reducing GERD symptoms, consumption of PPI, and esophageal acid exposure for up to 12 years of follow-up (5). Initially, MSA was mainly performed in patients with mild to moderate GERD presenting with no or minimal anatomical alterations and esophagitis grade B or less (6). Throughout the years, inclusion criteria have been expanded to include patients with hiatal hernia $>3 \mathrm{~cm}$, esophagitis $>$ grade $\mathrm{B}$, and Barrett's esophagus, but only a few studies have evaluated the outcomes of MSA in patients with severe GERD (7-11).

Pre-operative indicators of GERD severity have previously been defined based on manometric, $\mathrm{pH}$-monitoring, and endoscopic findings that may predict failure of a partial fundoplication. Of note, the pre-operative DeMeester $\mathrm{pH}$ score

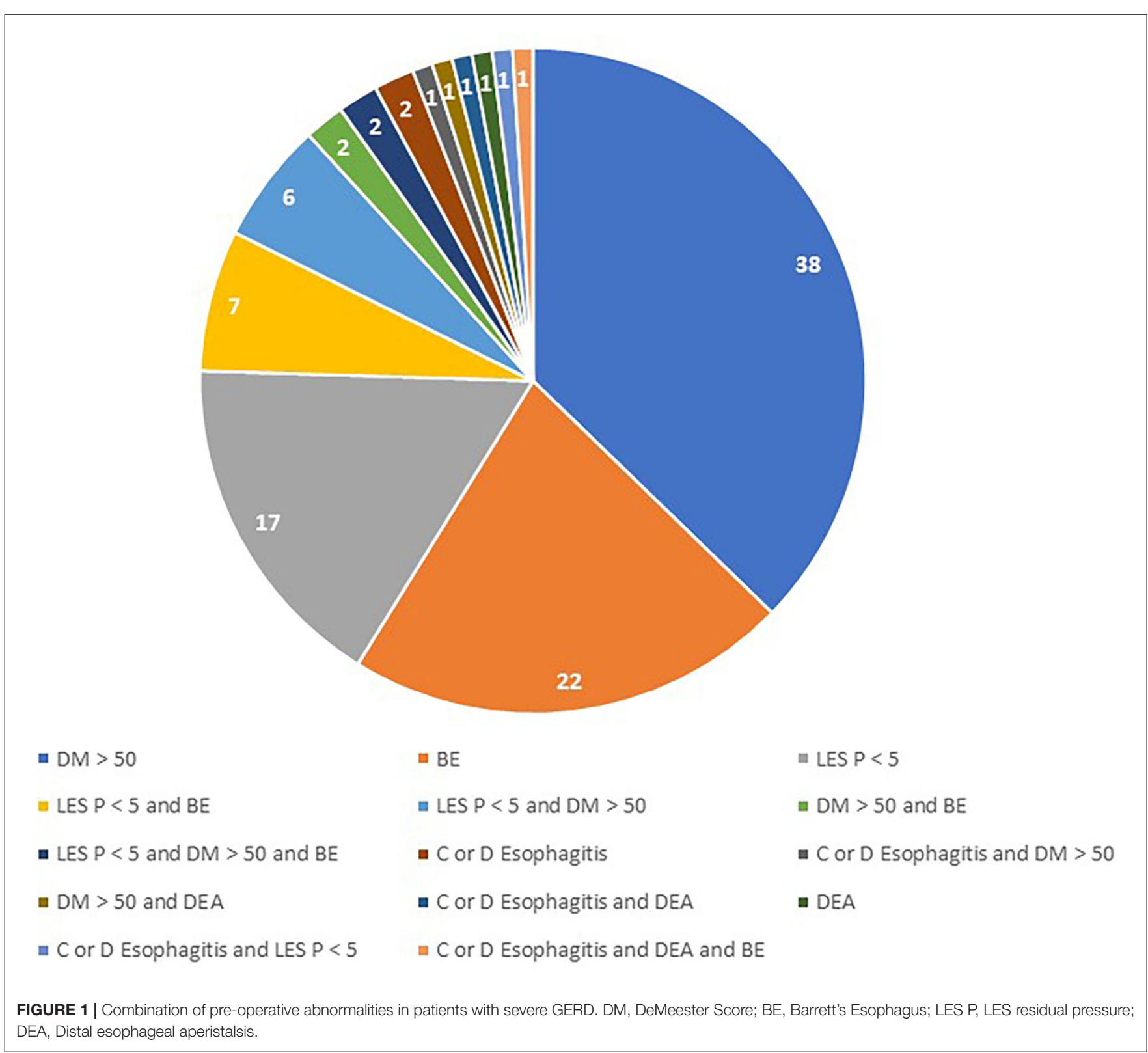


showed $86 \%$ sensitivity for predicting surgical failure (12). Aim of this study was to evaluate the short- and long-term effectiveness of MSA in patients with severe GERD compared with individuals with mild to moderate disease.

\section{MATERIALS AND METHODS}

A retrospective analysis was conducted using a prospectively collected database of patients who had undergone MSA implantation. The study protocol was approved by the Institutional Review Board. Inclusion criteria were age between 18 and 65 years and a minimum post-operative follow-up of 6 months. Exclusion criteria were previous esophagogastric surgery and documented allergy to titanium or nickel. Patients were included in the severe GERD group if one or more of the following conditions were present pre-operatively: LES basal pressure $<5 \mathrm{mmHg}$ or distal esophageal amplitude $<30$ $\mathrm{mmHg}$ on esophageal manometry, biopsy-proven Barrett's metaplasia, presence of stricture or grade C-D esophagitis on upper gastrointestinal endoscopy, and DeMeester score $>50$ on ambulatory esophageal $\mathrm{pH}$ monitoring (12). The remaining patients were included in the mild to moderate GERD group. Pre- and post-operative patient characteristics of the two patient groups were compared.

\section{Pre-operative Assessment}

All patients underwent clinical assessment by completing the gastroesophageal reflux disease health-related quality of life (GERD-HRQL) questionnaire on-PPI. The GERD-HRQL score is based on 10 questions and all queries have a score ranging from 0 to 5 . A GERD-HRQL score $>15$ is considered abnormal (13).

All patients also underwent a full diagnostic assessment including barium swallow study, endoscopy, esophageal $\mathrm{pH}$-monitoring or $\mathrm{pH}$-impedance off PPI, and esophageal manometry. Upper gastrointestinal endoscopy was performed to assess the presence of esophagitis according to the Los Angeles classification, biopsy-proven Barrett's esophagus, peptic stricture, or hiatus hernia. An esophageal $\mathrm{pH}$ or $\mathrm{pH}$-impedance study was performed using a trans-nasal catheter or a wireless system $\left(\mathrm{BRAVO}^{\mathrm{TM}}\right)$, and the DeMeester score and esophageal acid exposure time were collected. Standard or high-resolution esophageal manometry investigated Lower Esophageal Sphincter (LES) resting pressure, LES overall and abdominal length, and distal esophageal amplitude.

\section{Surgical Technique}

The laparoscopic MSA implantation was performed under general anesthesia, as previously described (14). The gastroesophageal junction is dissected, the posterior vagus nerve is identified and separated from the esophageal wall, and the esophagus is encircled with a Penrose drain. No short gastric vessels are divided. In patients with hiatal hernia $\geq 3 \mathrm{~cm}$, mediastinal dissection and posterior crural repair are routinely performed. The esophageal circumference is measured with a magnetic sizer device. The correct size of MSA is decided by increasing 2 or 3 beads from the point of sizer release. Finally, the MSA device (Linx Reflux Management System, Ethicon,
Johnson \& Johnson, Shoreview, Mn, USA) is inserted through the retroesophageal tunnel and locked anteriorly.

\section{Post-operative Follow-Up}

Patients underwent post-operative clinical assessment with GERD-HRQL and functional outcome swallowing scale (FOSS) questionnaire (15) to analyze reflux symptoms, quality of life, and dysphagia at 2 weeks, 6 months, and then each year after the operation. A FOSS score $>1$ identified severe post-operative

TABLE 2 | Baseline demographic and clinical data of patients with severe or non-severe GERD.

\begin{tabular}{lccc}
\hline & $\begin{array}{c}\text { Non-severe GERD } \\
(\boldsymbol{n}=\mathbf{2 3 4})\end{array}$ & $\begin{array}{c}\text { Severe GERD } \\
(\boldsymbol{n}=\mathbf{1 0 2})\end{array}$ & $\boldsymbol{p}$ \\
\hline Age, years & $45.2( \pm 13.8)$ & $46.2( \pm 13.3)$ & 0.5374 \\
Female, $n$ (\%) & $72(30.7)$ & $38(37.2)$ & 0.2435 \\
Body mass index, kg/m² & $24.8( \pm 3.7)$ & $25.3( \pm 3.9)$ & 0.2634 \\
Heartburn, $n$ (\%) & $192(82.1)$ & $81(79.4)$ & 0.5602 \\
Regurgitation, $n$ (\%) & $125(53.4)$ & $53(52)$ & 0.8134 \\
Dysphagia, $n$ (\%) & $13(5.5)$ & $12(11.7)$ & 0.0460 \\
Symptom duration (years) & $8.3( \pm 6.9)$ & $9.7( \pm 5.1)$ & 0.0665 \\
PPI use, $n$ (\%) & $167(71.3)$ & $88(86.2)$ & 0.0034 \\
PPI therapy (years) & $6.7( \pm 5.6)$ & $7.1( \pm 5.1)$ & 0.5369 \\
GERD-HRQL score & $19.2( \pm 7.7)$ & $21.0( \pm 7.5)$ & 0.0479 \\
Atypical symptoms, $n(\%)$ & $6(2.6)$ & $3(2.9)$ & 0.8760 \\
\hline
\end{tabular}

Continuous variables are expressed using mean values $( \pm S D)$.

TABLE 3 | Baseline pre-operative findings in patients with severe or non severe GERD.

\begin{tabular}{lccc}
\hline & $\begin{array}{c}\text { Non-severe GERD } \\
(\boldsymbol{n}=\mathbf{2 3 4})\end{array}$ & $\begin{array}{c}\text { Severe GERD } \\
(\boldsymbol{n}=\mathbf{1 0 2})\end{array}$ & $\boldsymbol{p}$ \\
\hline Hiatal hernia, $n(\%)$ & $177(75.6)$ & $84(82.3)$ & 0.1760 \\
Hiatal hernia, cm & $1.7( \pm 1.3)$ & $1.9( \pm 1.4)$ & 0.2062 \\
LES resting pressure, mmHg & $18.8( \pm 11.2)$ & $13.4( \pm 11.8)$ & 0.0001 \\
LES overall length, cm & $2.9( \pm 1.5)$ & $2.8( \pm 1.4)$ & 0.5669 \\
LES abdominal length, cm & $1.2( \pm 1.3)$ & $1.1( \pm 1.3)$ & 0.5172 \\
DEA, mmHg & $74.2( \pm 35.4)$ & $62.1( \pm 23.8)$ & 0.0018 \\
Total acid exposure time, \% & $6.5( \pm 3.7)$ & $13.3( \pm 9.3)$ & $<0.0001$ \\
DeMeester score & $26.2( \pm 12)$ & $58.3( \pm 33.5)$ & $<0.0001$
\end{tabular}

Continuous variables are expressed using mean values ( $\pm S D$ ).

TABLE 4 | Intraoperative and clinical course of patients with severe or non-severe GERD.

\begin{tabular}{lccc}
\hline & $\begin{array}{c}\text { Non-severe GERD } \\
(\boldsymbol{n}=\mathbf{2 3 4})\end{array}$ & $\begin{array}{c}\text { Severe GERD } \\
(\boldsymbol{n}=\mathbf{1 0 2})\end{array}$ & $\boldsymbol{p}$ \\
\hline Duration of intervention, min & $61.4(30)$ & $61.1(24.5)$ & 0.9292 \\
Number of beads & $13.9(1.3)$ & $14.1(1.4)$ & 0.2062 \\
Crural repair, $n$ (\%) & $94(40.2)$ & $50(49)$ & 0.1345 \\
Length hospital stay, days & $1.4(0.7)$ & $1.2(0.6)$ & 0.0125
\end{tabular}

Continuous variables are expressed using mean values (SD). 


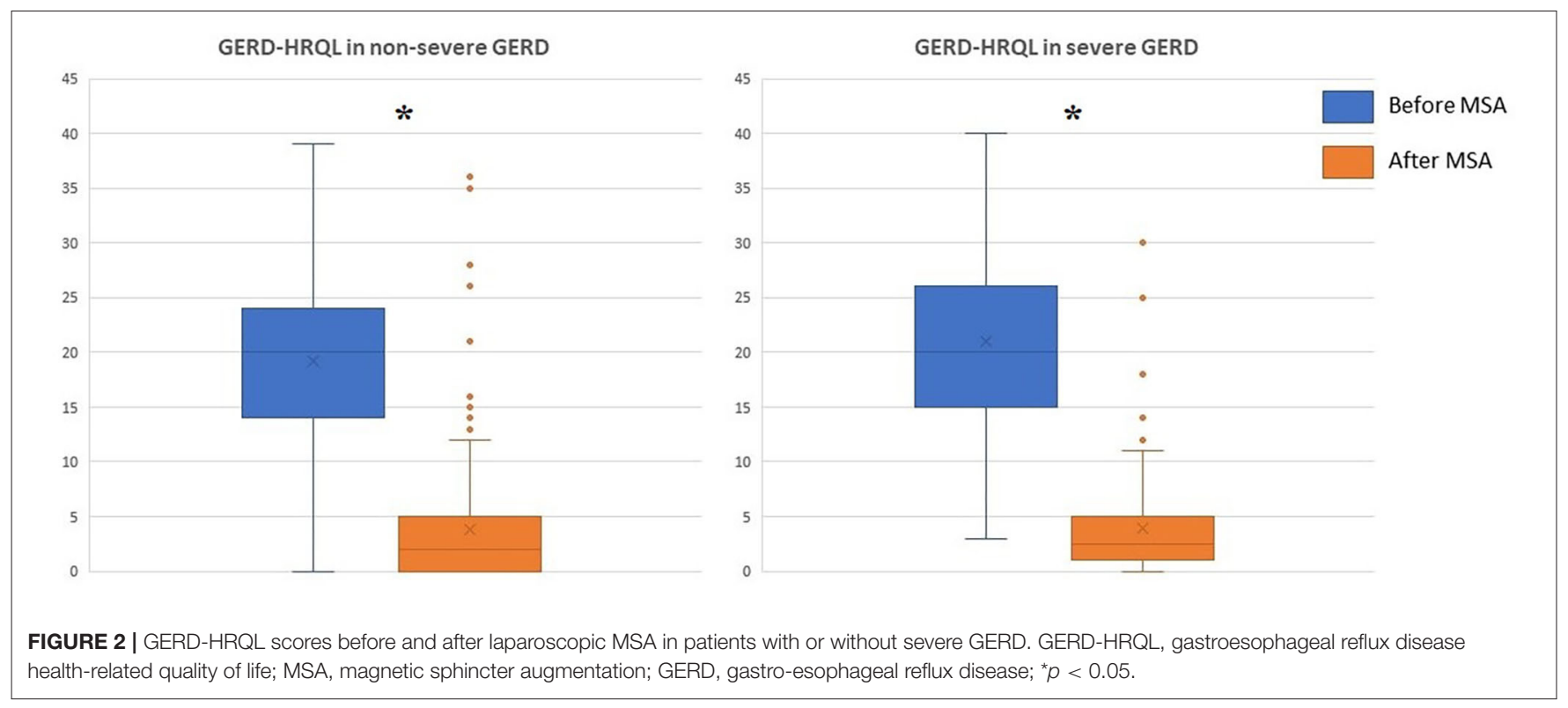

dysphagia. Upper gastrointestinal endoscopy, barium swallow study, esophageal manometry, and esophageal $\mathrm{pH}$ monitoring were performed between 6 and 12 months after surgery and repeated thereafter according to specific clinical circumstances or as a part of investigational studies.

\section{Statistical Analysis}

Continuous variables are reported as mean \pm standard deviation (SD) or median with interquartile range (IQR) when appropriate. Variables were compared between patients with mild to moderate GERD disease to patients with severe GERD, as defined before. Statistical analysis was performed through Wilcoxon test, MannWhitney $U$, Student's t test and Chi-square test as appropriate. When pre- and post-operative variables were compared, a twotailed paired Student's t test was used. A $p<0.05$ was considered statistically significant. Statistical analysis was performed using SPSS software 23.0 (IBM, Armonk, New York, U.S.).

\section{RESULTS}

A total of 336 (32.7\% female) patients were included in the study. Among them, 102 patients (30.4\%) met the criteria for inclusion in the severe GERD group. The main pre-operative reasons accounting for disease severity were DeMeester score $>50(49 \%$ of patients), biopsy-proven Barrett's metaplasia (33.3\%), and LES basal pressure $<5 \mathrm{mmHg}$ (27.5\%; Table 1). A total of 19 patients met two inclusion criteria, and three patients met three inclusion criteria. There were no patients with peptic esophageal strictures found at pre-operative endoscopy (Figure 1).

Demographic characteristics were similar in the two patient groups. However, patients with severe GERD had a higher rate of pre-operative dysphagia, higher scores of GERD-HRQL questionnaire, and higher PPI use (Table 2).

Table 3 shows that application of the study inclusion predicted disease severity, i.e., patients with severe GERD had lower
LES resting pressure, weaker peristaltic amplitude, and greater esophageal acid exposure compared to patients with mild disease. There were no significant differences regarding the intraoperative variables, except for post-operative length of hospital stay (Table 4).

The median follow-up was 24 months $(\mathrm{IQR}=75)$ and 32 months $(\mathrm{IQR}=84)$ in the severe and in the non-severe GERD group, respectively. In both groups, GERD-HRQL scores and use of PPI significantly decreased compared to baseline $(p<$ 0.05 ; Figures 2, 3). Post-operative outcomes and complications are shown in Table 5. Patients with severe GERD had a higher rate of occasional post-operative dysphagia (25.4 vs. $14.1 \%$, $p=0.0124$ ), but less individuals required device removal (8 vs. 24 patients, $p=$ NS; Figure 4). Overall, 122 patients underwent esophageal manometry at a median of 12 months $(\mathrm{IQR}=30)$ after surgery. The LES resting pressure significantly increased in both groups, but DEA increased more consistently and reached statistical significance only in patients with non-severe GERD. A total of 108 patients underwent post-operative esophageal $\mathrm{pH}$ monitoring at a median of 28 months $(\mathrm{IQR}=51)$ after surgery, $72(30.7 \%)$ in the non severe GERD group, and $36(35.5 \%)$ in the severe GERD group $(p=0.3871)$. No significant differences were found between the groups in terms of acid exposure time, DeMeester score, or number of patients with DeMeester score $>14.7$. However, there was a trend toward higher acid exposure in patients with pre-operative severe GERD (Figure 5).

\section{DISCUSSION}

This observational study shows that MSA is a safe and effective procedure in patients presenting with severe GERD and that clinical outcomes are similar to those observed in patients with mild to moderate disease (16). GERD is a spectrum disease presenting with different phenotypes. The goal of predicting surgical outcomes based on the presence of erosive esophagitis 


\section{PPI USE}

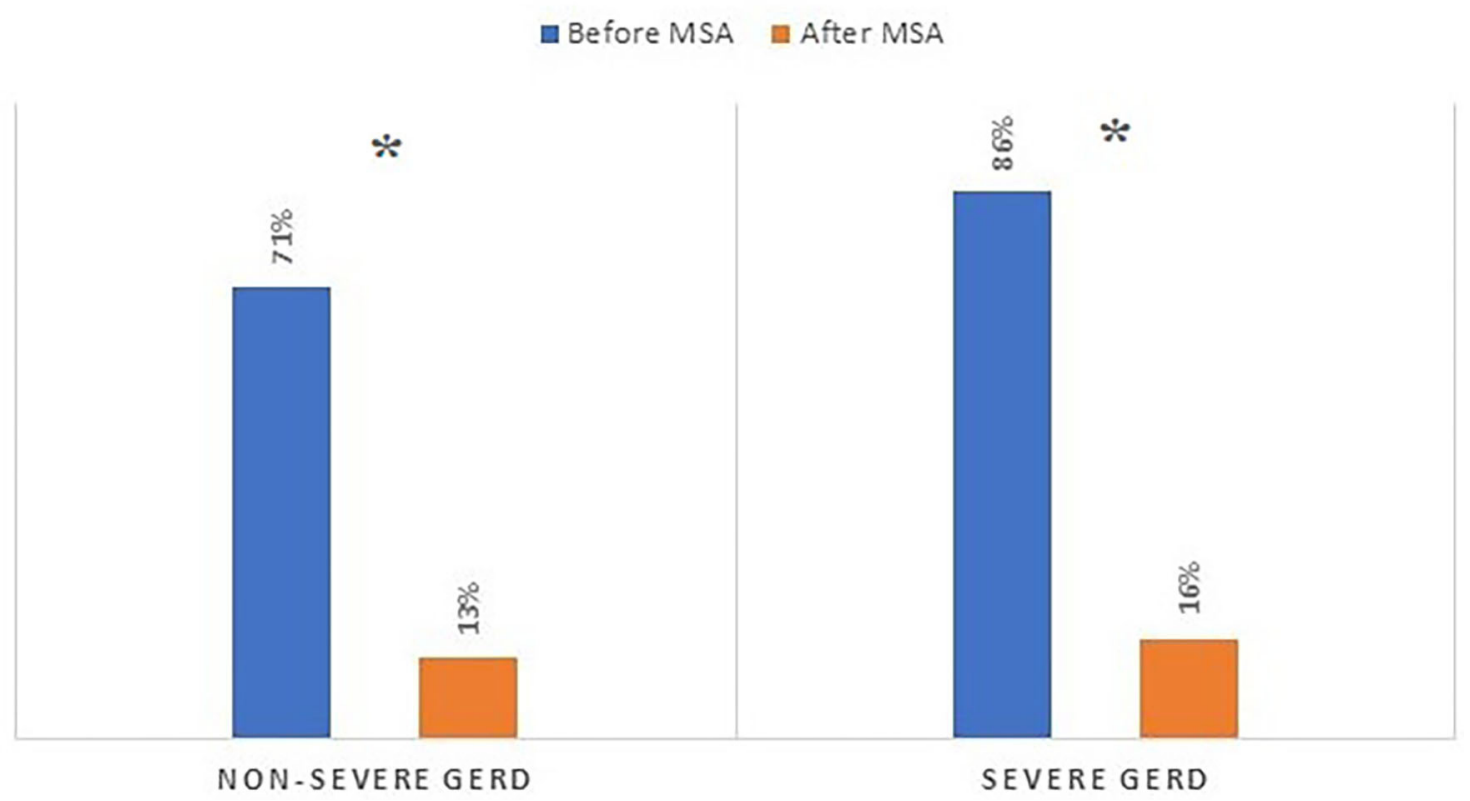

FIGURE 3 | PPI consumption before and after MSA procedure in patients with or without severe GERD. PPI, proton-pump inhibitors; MSA, magnetic sphincter augmentation; GERD, gastro-esophageal reflux disease; ${ }^{*} p<0.05$.

TABLE 5 | Post-operative outcomes in patients undergoing MSA for severe or non-severe GERD.

\begin{tabular}{|c|c|c|c|}
\hline & $\begin{array}{l}\text { Non-severe GERD } \\
(n=234)\end{array}$ & $\begin{array}{c}\text { Severe GERD } \\
(n=102)\end{array}$ & $p$ \\
\hline Follow-up, months & $50.8( \pm 44.2)$ & $49.6( \pm 43.7)$ & 0.8185 \\
\hline GERD-HRQL score & $3.8( \pm 5.7)$ & $3.9( \pm 4.8)$ & 0.8770 \\
\hline Use of PPI, $n(\%)$ & $31(13.2)$ & $16(15.6)$ & 0.5597 \\
\hline $\begin{array}{l}\text { Occasional post-operative } \\
\text { dysphagia, } n(\%)\end{array}$ & $33(14.1)$ & $26(25.4)$ & 0.0124 \\
\hline $\begin{array}{l}\text { Recurrent hiatal hernia, } \\
n(\%)\end{array}$ & $6(2.6)$ & $4(3.9)$ & 0.5209 \\
\hline Endoscopic dilation, $n$ (\%) & $5(2.1)$ & $3(2.9)$ & 0.6562 \\
\hline Device removal, $n$ (\%) & $24(10.2)$ & $8(7.8)$ & 0.4903 \\
\hline $\begin{array}{l}\text { LES resting pressure, } \\
\mathrm{mmHg}^{\delta}\end{array}$ & $24.3( \pm 10.4)$ & $21.4( \pm 12.3)$ & 0.0271 \\
\hline LES overall length, $\mathrm{cm}^{\delta}$ & $3.2( \pm 1.3)$ & $3.1( \pm 1.4)$ & 0.5270 \\
\hline LES abdominal length, $\mathrm{cm}^{\delta}$ & $1.4( \pm 1.4)$ & $1.4( \pm 1.5)$ & 1.0000 \\
\hline DEA, $\mathrm{mmHg}^{\delta}$ & $82.4( \pm 44.4)$ & $66.6( \pm 28.9)$ & 0.0011 \\
\hline Acid exposure time, \%* & $3.6( \pm 4.4)$ & $4.5( \pm 4.4)$ & 0.0856 \\
\hline DeMeester score ${ }^{\star}$ & $13.4( \pm 15.9)$ & $17( \pm 16.3)$ & 0.0591 \\
\hline DeMeester > 14.7, $n(\%)$ & $20(27.8)$ & $15(41.7)$ & 0.1476 \\
\hline
\end{tabular}

Continuous variables are expressed using mean values $( \pm S D) .{ }^{\delta} 122$ patients underwent post-operative esophageal manometry, 40 in the severe GERD group. ${ }^{*} 108$ patients underwent post-operative $\mathrm{pH}$ study, 36 in the severe GERD group.

has largely failed due to the difficulties in precisely recognizing the mucosal phenotype. In fact, most patients are treated with high-dose PPI which can masquerade the presence of erosive esophagitis. Finally, given the lack of a universally recognized definition of disease severity, using a more composite definition of severe GERD may in part resolve this problem and help in identifying patients at greater risk of progressive disease (17-19).

The goal of antireflux surgery is to restore competence of the esophagogastric junction, but laparoscopic Nissen and Toupet fundoplication carry the burden of post-operative side effects and high variability in outcomes (20-22). Horvath et al. described six independent measures of disease severity associated to surgical failure after laparoscopic Toupet fundoplication. Interestingly a pre-operative DeMeester score >50 was $86 \%$ sensitive for predicting surgical failure (12). More recently, Schwameis et al. (23) have stratified 334 patients undergoing MSA using the previous criteria. They found that MSA is an effective therapeutic option for patients with severe GERD as defined by a pre-operative DeMeester score $\geq 50$. Both patients' groups significantly improved at a mean follow-up of 13.6 months, but among patients with severe GERD the rate of distal esophageal acid exposure normalization tended to be lower $(p=$ $0.109)$ and more patients were using PPI $(p<0.041)$.

In the present study, patients with severe GERD undergoing MSA had excellent outcomes at a mean of 50 months of followup, with a significant improvement of GERD-HRQL scores and decreased PPI use compared to baseline. These results are similar to what we observed in our cohort of control patients with mild to moderate GERD. Interestingly, occasional dysphagia was more common in the severe GERD group, both in the pre- and in the post-operative period. This higher prevalence of pre-operative dysphagia may be explained by a motility 

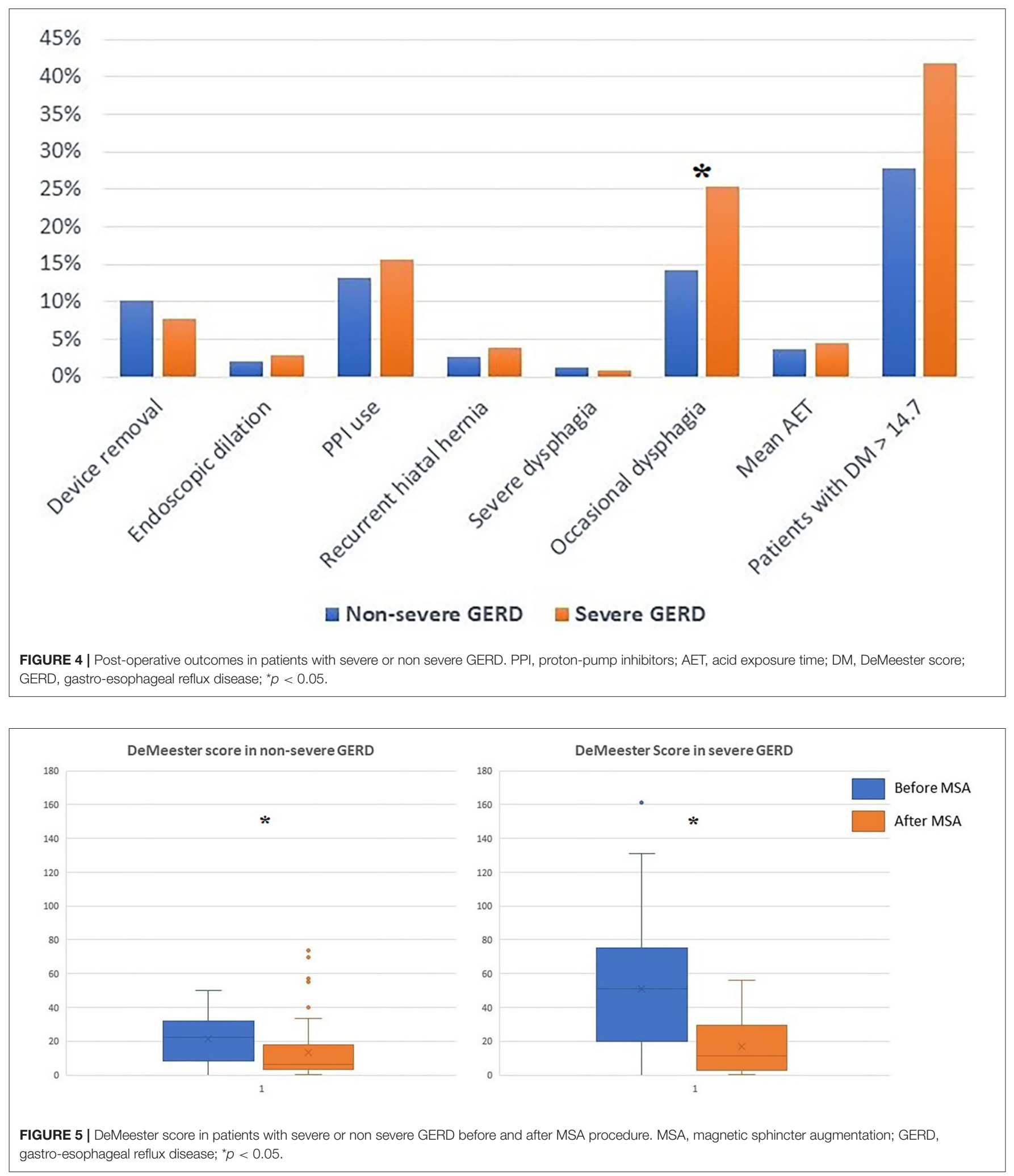

dysfunction induced by long-standing reflux or by an occasional diaphragmatic entrapment of a sliding hiatus hernia $(24,25)$. On the other hand, the higher rate of crural repair associated with
MSA implantation in patients with severe GERD may explain the significantly higher rate of post-operative dysphagia observed in these individuals. In fact, crural repair has an additive effect 
on LES augmentation, and the combination of hiatoplasty and MSA may increase the incidence of post-operative dysphagia $(26,27)$. Last but not least, there were no significant differences between the two patient groups regarding the post-operative rates of recurrent hiatal hernia, endoscopic dilation, and laparoscopic device removal. The most common reasons for explant were persistent heartburn/regurgitation (3.6\%), dysphagia (1.8\%), and erosion $(1.8 \%)$. There was no significant morbidity or mortality associated with these revisional laparoscopic procedures $(5,28)$.

Furthermore, a significant reduction in the DeMeester score compared to baseline was noted in both patient groups. Although there was a trend toward an abnormally higher post-operative score in the severe GERD group, the majority of these patients reached $\mathrm{pH}$ normalization. Despite the fact that even patients with severe GERD may benefit from MSA, we hypothesize that an earlier surgical intervention has the potential to prevent anatomical deterioration of the esophagogastric barrier and Barrett's mucosal changes (26). In two recent studies, age younger than 40-45 years, male sex, GERDHRQL total score $>15$, and abnormal DeMeester score were independent predictors of favorable outcome after MSA (5, 27).

The retrospective design of this research, the possible selection bias, and the lack of systematic post-operative ambulatory $\mathrm{pH}$ studies represent the main study limitations. Another intrinsic study limitation is the lack of a universally recognized definition of severe GERD.

In conclusion, the laparoscopic MSA procedure can safely be offered to patients with GERD regardless of the severity of the disease as assessed by a set of anatomic and physiologic

\section{REFERENCES}

1. Nirwan JS, Hasan SS, Babar ZUD, Conway BR, Ghori MU. Global prevalence and risk factors of gastro-oesophageal reflux disease (GORD): systematic review with meta-analysis. Sci Rep. (2020) 10:1-14. doi: 10.1038/s41598-020-62795-1

2. Watson DI, Baigrie RJ, Jamieson GG. A learning curve for laparoscopic fundoplication definable, avoidable, or a waste of time? Ann Surg. (1996) 224:198-203. doi: 10.1097/00000658-19960800000013

3. Gill J, Booth MI, Stratford J, Dehn TCB. The extended learning curve for laparoscopic fundoplication: a cohort analysis of 400 consecutive cases. J Gastrointest Surg. (2007) 11:487-92. doi: 10.1007/s11605-0070132-0

4. Bona D, Aiolfi A, Asti E, Bonavina L. Laparoscopic Toupet fundoplication for gastroesophageal reflux disease and hiatus hernia: proposal for standardization using the "critical view" concept. Updates Surg. (2020) 72:555-8. doi: 10.1007/s13304-020-00732-7

5. Ferrari D, Asti E, Lazzari V, Siboni S, Bernardi D, Bonavina L. Six to 12-year outcomes of magnetic sphincter augmentation for gastroesophageal reflux disease. Sci Rep. (2020) 10:13753. doi: 10.1038/s41598-020-70742-3

6. Bonavina L, Saino GI, Bona D, Lipham J, Ganz RA, Dunn D, et al. Magnetic augmentation of the lower esophageal sphincter: results of a feasibility clinical trial. J Gastrointest Surg. (2008) 12:2133-40. doi: 10.1007/s11605-0080698-1

7. Rona KA, Reynolds J, Schwameis K, Zehetner J, Samakar K, Oh P, et al. Efficacy of magnetic sphincter augmentation in patients with large hiatal hernias. Surg Endosc. (2017) 31:2096-102. doi: 10.1007/s00464-016-5204-3 indicators. However, further prospective studies with longer follow-up are needed and special caution is needed in individuals with long-standing Barrett's esophagus because of the risk of progression to dysplasia and cancer in spite of adequate reflux control.

\section{DATA AVAILABILITY STATEMENT}

The raw data supporting the conclusions of this article will be made available by the authors, without undue reservation.

\section{ETHICS STATEMENT}

Ethical review and approval was not required for the study on human participants in accordance with the local legislation and institutional requirements. The patients/participants provided their written informed consent to participate in this study.

\section{AUTHOR CONTRIBUTIONS}

DF and LB designed the study, analyzed the data, and were major contributors in writing and reviewing the manuscript. SS, CR, $\mathrm{AL}$, and GG searched the literature, made the statistical analysis, and reviewed the manuscript. All authors contributed to the article and approved the submitted version.

\section{FUNDING}

This study was supported by A.I.R.ES. (Associazione Italiana Ricerca ESofago).
8. Dunn CP, Henning JC, Sterris JA, Won P, Houghton C, Bildzukewicz NA, et al. Regression of Barrett's esophagus after magnetic sphincter augmentation: intermediate-term results. Surg Endosc. (2021) 35:580409. doi: 10.1007/s00464-020-08074-6

9. Schwameis K, Nikolic M, Morales Castellano DG, Steindl A, Macheck S, Riegler M, et al. Crural closure improves outcomes of magnetic sphincter augmentation in GERD patients with hiatal hernia. Sci Rep. (2018) 8:7319. doi: 10.1038/s41598-01824322-1

10. Tatum JM, Alicuben E, Bildzukewicz N, Samakar K, Houghton CC, Lipham JC, et al. Minimal versus obligatory dissection of the diaphragmatic hiatus during magnetic sphincter augmentation surgery. Surg Endosc. (2019) 33:78288. doi: 10.1007/s00464-018-6343-5

11. Ayazi S, Chowdhury N, Zaidi AH, Chovanec K, Komatsu Y, Omsteas AN, et al. Magnetic sphincter augmentation (MSA) in patients with hiatal hernia: clinical outcome and patterns of recurrence. Surg Endosc. (2019) 34:183546. doi: 10.1007/s00464-019-06950-4

12. Horvath KD, Jobe BA, Herron DM, Swanstrom LL. Laparoscopic toupet fundoplication is an inadequate procedure for patients with severe reflux disease. J Gastrointest Surg. (1999) 3:58391. doi: 10.1016/S1091-255X(99)80079-1

13. Velanovich V. The development of the GERD-HRQL symptom severity instrument. Dis Esophagus. (2007) 20:1304. doi: 10.1111/j.1442-2050.2007.00658.x

14. Bonavina L, Saino G, Bona D, Sironi A, Lazzari V. One hundred consecutive patients treated with magnetic sphincter augmentation for gastroesophageal reflux disease: 6 years of clinical experience from a single center. $\mathrm{J}$ Am Coll Surg. (2013) 217:577-85. doi: 10.1016/j.jamcollsurg.2013.04.039 
15. Salassa JR. A functional outcome swallowing scale for staging oropharyngeal dysphagia. Dig Dis. (1999) 17:230-4. doi: 10.1159/000016941

16. Saino G, Bonavina L, Lipham J, Dunn D, Ganz RA. Magnetic sphincter augmentation for gastroesophageal reflux at 5 years: final results of a pilot study show long-term acid reduction and symptom improvement. $J$ Laparoendosc Adv Surg Tech. (2015) 25:787-92. doi: 10.1089/lap.2015.0394

17. Triadafilopoulos G, Clarke JO, Hawn M. Precision GERD management for the 21st century. Dis Esophagus. (2017) 39:1-6. doi: 10.1093/dote/dox079

18. Savarino E, de Bortoli N, De Cassan C, Della Colletta M, Bartolo O, Furnari M, et al. The natural history of gastro-esophageal reflux disease. Dis Esophagus. (2017) 30:1-9. doi: 10.1111/dote.12511

19. Gyawali CP, Kahrilas PJ, Savarino E, Zerbib F, Mion F, Smout AJPM, et al. Modern diagnosis of GERD: the Lyon consensus. Gut. (2018) 67:135162. doi: 10.1136/gutjnl-2017-314722

20. Khajanchee YS, O'Rourke R, Cassera MA, Gatta P, Hansen PD, Swanström LL. Laparoscopic reintervention for failed antireflux surgery: subjective and objective outcomes in 176 consecutive patients. Arch Surg. (2007) 142:78591. doi: 10.1001/archsurg.142.8.785

21. Richter JE, Dempsey DT. Laparoscopic antireflux surgery: key to success in the community setting. Am J Gastroenterol. (2008) 103:289-91. doi: 10.1111/j.1572-0241.2007.01602.x

22. Schwameis K, Zehetner J, Rona K, Crookes P, Bildzukewicz N, Oh DS, et al. Post-nissen dysphagia and bloating syndrome: outcomes after conversion to toupet fundoplication. J Gastrointest Surg. (2017) 21:4415. doi: 10.1007/s11605-016-3320-y

23. Schwameis K, Ayazi S, Zheng P, Grubic AD, Salvitti M, Hoppo $\mathrm{T}$, et al. Efficacy of magnetic sphincter augmentation across the spectrum of GERD disease severity. J Am Coll Surg. (2021) 232:288-97. doi: 10.1016/j.jamcollsurg.2020.11.012

24. Ayazi S, Zheng P, Zaidi AH, Chovanec K, Chowdhury N, Salvitti $\mathrm{M}$, et al. Magnetic sphincter augmentation and postoperative dysphagia: characterization, clinical risk factors, and management. $J$ Gastrointest Surg. (2020) 24:39-49. doi: 10.1007/s11605-019-0 4331-9
25. Riva CG, Siboni S, Sozzi M, Lazzari V, Asti E, Bonavina L. High-resolution manometry findings after Linx procedure for gastro-esophageal reflux disease. Neurogastroenterol Motil. (2020) 32:e13750. doi: 10.1111/nmo.13750

26. Bonavina L, Fisichella PM, Gavini S, Lee YY, Tatum RP. Clinical course of gastroesophageal reflux disease and impact of treatment in symptomatic young patients. Ann N Y Acad Sci. (2020) 1481:11726. doi: $10.1111 /$ nyas. 14350

27. Ayazi S, Zheng P, Zaidi AH, Chovanec K, Salvitti M, Newhams $\mathrm{K}$, et al. Clinical outcomes and predictors of favorable result after laparoscopic magnetic sphincter augmentation: single-institution experience with more than 500 patients. J Am Coll Surg. (2020) 230:733-43. doi: 10.1016/j.jamcollsurg.2020.01.026

28. Asti E, Siboni S, Lazzari V, Bonitta G, Bonavina L. Removal of the magnetic sphincter device. Surgical technique and results of a single-center cohort study. Ann Surg. (2017) 265:941-5. doi: 10.1097/SLA.0000000000001785

Conflict of Interest: The authors declare that the research was conducted in the absence of any commercial or financial relationships that could be construed as a potential conflict of interest.

Publisher's Note: All claims expressed in this article are solely those of the authors and do not necessarily represent those of their affiliated organizations, or those of the publisher, the editors and the reviewers. Any product that may be evaluated in this article, or claim that may be made by its manufacturer, is not guaranteed or endorsed by the publisher.

Copyright (C) 2021 Ferrari, Siboni, Riva, Guerrazzi, Lovece and Bonavina. This is an open-access article distributed under the terms of the Creative Commons Attribution License (CC BY). The use, distribution or reproduction in other forums is permitted, provided the original author(s) and the copyright owner(s) are credited and that the original publication in this journal is cited, in accordance with accepted academic practice. No use, distribution or reproduction is permitted which does not comply with these terms. 